\title{
O PLANO NACIONAL DE FORMAÇÃO DE PROFESSORES DA EDUCAÇÃO BÁSICA (PARFOR): O IDEAL E A REALIDADE VIGENTE
}

\author{
CARDOSO, Elisângela Andrade Moreira ${ }^{1 *}$; NUNES, Cláudio Pinto ${ }^{1 * *}$ \\ ${ }^{1}$ Universidade do Sudoeste da Bahia \\ elisangelajg@gmail.com* \\ claudionunesba@hotmail.com ${ }^{* *}$
}

\section{RESUMO}

Este artigo discorre sobre a política de formação inicial para professores da Educação Básica, analisando o Plano Nacional de Formação de Professores da Educação Básica e suas contribuições para a formação inicial de docentes que não possuem a habilitação exigida pela Lei de Diretrizes e Bases da Educação Nacional. Para tanto, adotou-se a revisão de literatura para analisar o referido Plano em fontes documentais. As reflexões desencadeadas por essa revisão literária permitiram conhecer os aspectos legais que norteiam o percurso de formação inicial dos professores e também reconhecer $\mathrm{o}$ suscitado Plano como um instrumento importante para o professor em formação, como profissional competente, responsável e comprometido com a docência, a melhoria da qualidade na educação e as transformações sociais. Contudo, apesar de esse Plano ser uma iniciativa assertiva, apresenta limitações que convergem para a necessidade de uma reavaliação tanto dos princípios quanto dos objetivos propostos, com vistas ao redimensionamento para o sucesso, uma vez que esse Plano faz parte de uma ação inovadora da educação no Brasil.

PALAVRAS-CHAVE: Professores da Educação Básica. Formação inicial de professores. Parfor.

\section{THE NATIONAL PLAN FOR TEACHER TRAINING OF BASIC EDUCATION (PARFOR):} THE IDEAL AND THE RULING REALITY

\section{ABSTRACT}

This article discusses the initial training policy for teachers of basic education, analyzing the National Plan for the Education of Basic Education Teachers and their contributions to the initial training of teachers who do not have the qualification required by the National Education Guidelines and Bases Law. For this purpose, the literature review was adopted to analyze the Plan in documentary sources. The reflections triggered by this literary review allowed to know the legal aspects that guide the initial training course of teachers and also to recognize the raised Plan as an important instrument for the teacher in training, as a competent professional, responsible and committed to teaching, improvement quality in education and socia change. However, although this Plan is an assertive initiative, it presents limitations that converge on the need for a reassessment of both the principles and the proposed objectives, with a view to re-scaling for success, since this Plan is part of an innovative action of education in the Brazil. KEYWORDS: Teacher of basic education. Initial teacher training. Parfor.

\section{EL PLAN NACIONAL DE FORMACIÓN DE MAESTROS DE LA EDUCACIÓN BÁSICA (PARFOR): EL IDEAL Y LA READIDAD VIGENTE}

\section{RESUMEN}

Este artículo discurre sobre la política de formación inicial para profesores de la educación básica, analizando el Plan Nacional de Formación de Profesores de la Educación Básica y sus contribuciones a la formación inicial de docentes que no poseen la habilitación exigida por la Ley de Directrices y Bases de la Educación Nacional. Para ello, se adoptó la revisión de literatura para analizar el referido Plan en fuentes documentales. Las reflexiones desencadenadas por esta revisión literaria permitieron conocer los aspectos legales que orientan el recorrido de formación inicial de los profesores y también reconocer el suscitado Plan como un instrumento importante para el profesor en formación, como profesional competente, responsable y comprometido con la docencia, la mejora de la calidad en la educación y las transformaciones sociales. Sin embargo, pese al hecho de que este Plan es una iniciativa asertiva, presenta limitaciones que convergen en la necesidad de una reevaluación tanto de los principios y de los objetivos propuestos, con vistas al redimensionamiento para el éxito, ya que ese Plan forma parte de una acción innovadora de la educación en el país.

PALABRAS CLAVE: Profesores de la educación básica. Formación inicial de maestros. Parfor. 


\section{INTRODUÇÃO}

Inúmeras reflexões sobre a formação de professores da Educação Básica têm se constituído no cenário brasileiro, principalmente após a implantação da vigente Lei de Diretrizes e Bases da Educação Nacional (LDBEN) - Lei no 9.394/1996 -, que impulsionou esse nível de formação para o Ensino Superior.

Formar professores com qualidades acadêmicas sociais, compromisso político voltado para as transformações educacionais e sociais, bem como a adequação às novas tecnologias e, sobretudo, a aplicabilidade dos conhecimentos adquiridos no processo de formação dos educandos, é o grande desafio das universidades nos cursos de licenciatura em meio às provocações da sociedade contemporânea. Nesse cenário, foi instituído o Plano Nacional de Formação de Professores da Educação Básica (Parfor), com a finalidade de colaborar com a formação inicial dos professores em exercício que não possuem a graduação específica para sua atuação.

No entanto, esse Programa possui questões subjetivas que precisam ser analisadas e discutidas, uma vez que a formação de professores possibilita ao docente adequação e atualização de sua prática, contribuindo, assim, para a superação dos problemas não apenas educacionais, mas também sociais, o que recai, consequentemente, sobre a qualidade educacional.

A formação de professor foi escolhida como objeto de estudo desta pesquisa pela necessidade de aprofundar a reflexão sobre o impacto desse Programa em andamento no Brasil, oferecido aos professores da Educação Básica em nível superior nas diversas instituições públicas nacionais. Para tanto, foram definidas algumas especificidades do professor em formação na Educação Superior, fundamentadas nas políticas públicas instituídas para a educação brasileira, sobretudo o Parfor, com a finalidade de aprofundar os conhecimentos mesclados pelos entraves e conquistas desse Plano.

Na esteira do sistema educacional, novas exigências surgem na perspectiva de integrá-lo aos mais distintos paradigmas propulsores do desenvolvimento que são imbricados ora pelas propostas tecnológicas, ora pela apreensão e produção do conhecimento. Ao discutirem sobre a formação do professor, Libâneo e Pimenta (1999, p. 260) já diziam que “[...] não é qualquer um que pode ser professor", visto que o professor necessita ser formado. Nesse contexto, encontram-se os

Educação \& Formação, Fortaleza, v. 2, n. 6, p. 54-69, set./dez. 2017

DOI: http://dx.doi.org/10.25053/edufor.v2i6.2011

http://seer.uece.br/redufor 
protagonistas desse embate, os profissionais da educação, que tentam, na medida do possível, compreender as ocorrências e os desfechos para tantas mazelas sociais e, através de suas ações, reforçam suas práticas e contribuem para o desenvolvimento das habilidades e competências de seus educandos no tocante ao processo de ensino-aprendizagem.

No contexto atual, faz-se necessário assimilar o conhecimento à complexidade do inacabado, visto que o profissional da docência deve vislumbrar o conhecimento como um processo contínuo que se constrói e reconstrói a partir das aspirações presentes em seu exercício (FREIRE, 2006). Portanto, a educação é um compromisso fundamentado em reflexões e relações pessoais e interpessoais permeadas pelos valores morais, éticos e sociais que envolvem toda a sociedade, sendo a escola um espaço privilegiado para aprimorar esses valores em meio a discussões e tomadas de decisão voltadas para a supressão dos problemas sociais, que excedem práticas conservadoras firmadas na transmissão de conhecimentos e na memorização de determinados conteúdos considerados absolutos.

No bojo das discussões educacionais, emergem necessidades vitais para o desenvolvimento da educação em todo o país; com isso, a LDBEN no 9.394/1996, em seu artigo 62, estabelece que "[...] A formação de docentes para atuar na Educação Básica far-se-á em nível superior, em curso de licenciatura, de graduação plena, em universidades e institutos superiores de educação [...]", porém, apesar de aceitar o nível médio como formação mínima para atuação na Educação Infantil e nas séries iniciais do Ensino Fundamental, essa mesma lei, em seu parágrafo 4ํ, artigo 87, determinou que: “[...] Até o fim da Década da Educação somente serão admitidos professores habilitados em nível superior ou formados por treinamento em serviço". No entanto, o prazo estipulado acabou em 2006, e essa meta ainda não foi cumprida entre os municípios brasileiros (BRASIL, 1996).

Muitas mudanças nortearam a trajetória de formação dos professores no cenário brasileiro por meio do aprofundamento das políticas implantadas, como a LDBEN no 9.394/1996, as várias diretrizes, os muitos pareceres e os diversos programas, entre outros documentos, que apontam os processos formativos dos professores como precedente para melhorar a qualidade da Educação Básica. O Governo Federal designou a Política Nacional de Formação de Professores do Magistério da Educação Básica por meio do Decreto no 6.755, de 29 de janeiro de 2009, constituindo, com essa política, o Parfor, em 30 de junho de 2009, com o objetivo de "[...] 
organizar, em regime de colaboração entre a União, os Estados, o Distrito Federal e os Municípios, a formação inicial e continuada dos profissionais do Magistério para as redes públicas da Educação Básica". Portanto, esse Plano oferece cursos de licenciatura na modalidade presencial, conferindo à primeira licenciatura o maior número de cursos destinados aos professores que não possuem formação de nível superior e à segunda licenciatura uma quantidade menor de cursos para os professores que possuem cursos de licenciatura, mas encontram-se atuando fora de sua área de formação (BRASIL, 2009a).

Como aporte teórico, recorreu-se aos principais documentos legais que definem as políticas nacionais para a formação de professores no cenário brasileiro. Quanto à base metodológica, esta pesquisa caracteriza-se como pesquisa qualitativa, amparando-se na perspectiva da dialética como referência para a análise dos dados, visto que "[...] a dialética é o pensamento crítico que se propõe a compreender a 'coisa em si' e sistematicamente se pergunta como é possível chegar à compreensão da realidade" (KOSIK, 2002, p. 20), além de admitir que o homem seja construtor de sua própria história.

\section{POLÍTICAS DE FORMAÇÃO DE PROFISSIONAIS DO MAGISTÉRIO DA EDUCAÇÃO BÁSICA NO BRASIL}

As políticas educacionais brasileiras, especialmente as que contemplam os programas especiais, apresentam problemas desde a sua elaboração, visto que tais propostas anseiam retificar os desajustes observados no cenário educacional. No entanto, estes continuam aquém das garantias para o alcance dos resultados de grande impacto; não obstante a isso, nota-se que a política de formação de professores no Brasil começou a ocorrer de forma tardia, não sendo, portanto, lugar de destaque nas políticas educacionais ao longo de sua história.

Destarte, o Plano de Desenvolvimento da Educação (PDE) apresentado pelo Ministério da Educação (MEC) em abril de 2007 disponibilizou ao Distrito Federal, estados e municípios instrumentos para avaliação e implementação de políticas que visem à melhoria da qualidade da educação, principalmente da Educação Básica do sistema público. A partir de então, as transferências voluntárias e a assistência técnica do MEC aos municípios, estados e Distrito Federal estão vinculadas à adesão ao Plano de Metas, intitulado "Compromisso Todos pela Educação", e à 
elaboração do Plano de Ações Articuladas (PAR), que são instrumentos essenciais para a melhoria do Índice de Desenvolvimento da Educação Básica (Ideb).

No tocante às políticas de formação de professores, o MEC desenvolveu alguns programas, como: o Programa de Formação de Professores em Exercício (Proformação), em 1997, com a finalidade de habilitar para o magistério, em nível médio, na modalidade normal, os professores que exercem atividades docentes tanto nas séries iniciais do Ensino Fundamental quanto na Educação de Jovens e Adultos (EJA); a Rede Nacional de Formação Continuada de Professores (Renafor), em 2004, com o intuito de contribuir para a melhoria da formação tanto dos professores quanto dos alunos; o Programa de Formação Inicial para os Professores em Exercício na Educação Infantil (Proinfantil), em 2004, que teve como referência a metodologia adotada no Proformação, porém destinado aos professores da Educação Infantil que não possuem a formação mínima exigida pela legislação brasileira; o Programa Nacional de Incentivo à Formação Continuada de Professores do Ensino Médio (Proifem), em 2004, com o propósito de permitir que o professor se atualize e aprofunde conhecimentos sobre as questões pedagógicas relativas ao Ensino Médio; o Programa de Formação Inicial para Professores dos Ensinos Fundamental e Médio (Prolicenciatura), em 2005, que oferece formação inicial a distância para os professores em exercício nos anos/séries finais do Ensino Fundamental ou Ensino Médio dos sistemas públicos de ensino; o Programa de Formação Continuada de Professores que atuam nos anos/séries iniciais do Ensino Fundamental (Proletramento), em 2006, visando à melhoria do ensino e da aprendizagem dos alunos em leitura, escrita e matemática, entre outros que objetivaram o combate do fracasso escolar (BRASIL, 2005).

De acordo com o MEC, em 2013 todos os 26 estados, o Distrito Federal e os 5.563 municípios assinaram o Termo de Adesão ao Plano de Metas Compromisso Todos pela Educação. Esse plano foi instituído pelo Decreto no 6.094, de 24 de abril de 2007, sendo concebido como um programa estratégico do PDE/MEC capaz de implantar um novo regime de colaboração em virtude da atuação dos entes federados sem comprometer a autonomia dos envolvidos, a decisão política, a ação técnica e o atendimento da demanda educacional, tudo isso com a finalidade de melhorar os indicadores educacionais.

O PAR alvitra políticas voltadas para a primeira licenciatura destinada aos professores em exercício na Educação Básica e que não possuem nenhuma graduação, a segunda licenciatura para 
aqueles que atuam na Educação Básica, mas estão fora da sua área de formação específica, e a formação pedagógica destinada aos bacharéis que exercem a profissão docente na Educação Básica.

Assim, a formação de professores com vistas à qualidade social, ao domínio e à aplicabilidade das tecnologias inovadoras, bem como o compromisso político, cuja finalidade consiste na transformação da sociedade, é considerada um dos grandes desafios na busca por respostas às questões da sociedade contemporânea; desafios estes enfrentados pelas universidades nos cursos de licenciatura no país.

Por fim, no dia 5 de abril de 2013 foi publicada a Lei $n$ ㅇ 12.796, que ajusta a vigente LDBEN à Emenda Constitucional (EC) no 59/2009, tornando obrigatória a oferta gratuita de Educação Básica a partir dos 4 anos de idade. A Lei no 12.796/2013 dispõe também sobre a formação do profissional da Educação Básica pública e dá outras providências, como:

\begin{abstract}
Art. 62. A formação de docentes para atuar na educação básica far-se-á em nível superior, em curso de licenciatura, de graduação plena, em universidades e institutos superiores de educação, admitida, como formação mínima para o exercício do magistério na educação infantil e nos 5 (cinco) primeiros anos do ensino fundamental, a oferecida em nível médio na modalidade normal. [...] § 4 A União, o Distrito Federal, os Estados e os Municípios adotarão mecanismos facilitadores de acesso e permanência em cursos de formação de docentes em nível superior para atuar na educação básica pública. § 5 A União, o Distrito Federal, os Estados e os Municípios incentivarão a formação de profissionais do magistério para atuar na educação básica pública mediante programa institucional de bolsa de iniciação à docência a estudantes matriculados em cursos de licenciatura, de graduação plena, nas instituições de educação superior. § 60 O Ministério da Educação poderá estabelecer nota mínima em exame nacional aplicado aos concluintes do ensino médio como pré-requisito para o ingresso em cursos de graduação para formação de docentes, ouvido o Conselho Nacional de Educação - CNE. (BRASIL, 2013, grifou-se).
\end{abstract}

Percebe-se, portanto, que a União, os estados e os municípios têm a obrigação de promover a formação superior dos professores por meio de bolsas de estudo. No entanto, essa iniciativa apontada na LDBEN é legitimada nessa nova lei, mas, na verdade, o Governo Federal já dispunha dessa prática desde 2010, por meio do Programa Institucional de Bolsa de Iniciação à Docência (Pibid), instituído pelo Decreto no 7.219, de 24 de junho de 2010.

\title{
3 DECRETO № 6.755/2009
}

Em 2009, uma das ações do PDE foi regulamentada por meio do Decreto no 6.755, de 29 de janeiro. Esse decreto surgiu para consolidar a Política Nacional de Formação de Professores da 
Educação Básica, disciplinando a atuação da Coordenação de Aperfeiçoamento de Pessoal de Nível Superior (Capes) no fomento a programas de formação inicial e continuada. Seu artigo 1으 institui que:

[...] a Política Nacional de Formação de Profissionais do Magistério da Educação Básica, com a finalidade de organizar, em regime de colaboração entre a União, os Estados, o Distrito Federal e os Municípios, a formação inicial e continuada dos profissionais do magistério para as redes públicas da educação básica. (BRASIL, 2009a).

Nesse contexto, o Parfor surge como resultado do PDE e do PAR em parceria com os estados acerca dos diagnósticos dos sistemas locais e das demandas oriundas da formação de professores, por meio do Decreto no 6.755/2009, que instituiu a Política Nacional de Formação dos Profissionais do Magistério da Educação Básica, com o objetivo de organizar os planos estratégicos da formação inicial e continuada, acordados nos Fóruns Estaduais Permanentes de Apoio à Formação Docente de cada estado e do Distrito Federal (BRZEZINSKI, 2010 apud ABDALLA, 2012), fundamentado na contribuição das Instituições Públicas de Educação Superior (Ipes) e instituindo a Capes como responsável pela indução, fomento e avaliação dos cursos.

A Resolução no 1, do Conselho Nacional de Educação, de 11 de fevereiro de 2009, que estabelece as diretrizes operacionais para a implantação do Programa Emergencial de Segunda Licenciatura para professores em exercício na Educação Básica pública, foi um complemento das ações do PDE em relação à formação de professores, a qual assegura, em seu artigo 2ำ, que o “[...] programa destina-se aos professores em exercício na Educação Básica pública há pelo menos três anos em área distinta da sua formação inicial". E, por meio da Portaria Normativa no 9, de 30 de junho de 2009, o Plano Nacional de Formação dos Professores da Educação Básica foi instituído no âmbito do MEC.

No dia 6 de agosto de 2009, a LDBEN foi alterada, merecendo destaque o artigo 61, que passou a definir o "profissional de educação", incluindo nessa "categoria" os profissionais com habilitação para lecionar da Educação Infantil ao Ensino Médio, os pedagogos habilitados em administração, planejamento, supervisão, inspeção e orientação educacional e os "portadores de diploma de curso técnico ou superior em área pedagógica ou afim habilitados" que atuam na área educacional. No dia 13 de outubro de 2009, foi sancionada a Lei no 12.056 , que acrescenta parágrafos ao artigo 62 da LDBEN, a saber:

Educação \& Formação, Fortaleza, v. 2, n. 6, p. 54-69, set./dez. 2017 
§ 1 - A União, o Distrito Federal, os Estados e os Municípios, em regime de colaboração, deverão promover a formação inicial, a continuada e a capacitação dos profissionais de magistério. § 2o - A formação continuada e a capacitação dos profissionais de magistério poderão utilizar recursos e tecnologias de educação a distância. § 3o - A formação inicial de profissionais de magistério dará preferência ao ensino presencial, subsidiariamente fazendo uso de recursos e tecnologias de educação a distância.

O caput do artigo 62 LDBEN refere-se à habilitação necessária para o professor da Educação Básica, que engloba a Educação Infantil, o Ensino Fundamental e o Ensino Médio. A inserção dos três parágrafos pela Lei no 12.056/2009 reforça a necessidade de investimento na formação do profissional da educação e obriga as instâncias federativas para a promoção da formação inicial e continuada, bem como para a capacitação dos profissionais do magistério. Essa lei prestigiou a modalidade de educação a distância como ferramenta dessa formação continuada e da capacitação desses professores, sendo que a formação inicial do professor deverá ser realizada preferencialmente no ensino presencial e a educação a distância será como uma complementação e aperfeiçoamento profissional.

No Brasil, a formação de professores da Educação Básica é normatizada por meio da organização de documentos legais que se articulam para dar sustentação a uma política nacional que almeja não apenas a formação inicial mínima para o exercício do magistério nos diferentes níveis e modalidades da educação e do ensino, mas também a promoção da formação continuada para os profissionais do magistério da Educação Básica, numa conjectura que caminha rumo à "[...] equalização de oportunidades educacionais e padrão mínimo de qualidade do ensino" (BRASIL, 2008, grifo nosso), conforme evidencia o trecho a seguir:

Art. 211. A União, os Estados, o Distrito Federal e os Municípios organizarão em regime de colaboração seus sistemas de ensino. (EC no 14/96 e EC n으5/2006). § 10 A União organizará o sistema federal de ensino e o dos Territórios, financiará as instituições de ensino públicas federais e exercerá, em matéria educacional, função distributiva e supletiva, de forma a garantir equalização de oportunidades educacionais e padrão mínimo de qualidade do ensino mediante assistência técnica e financeira aos Estados, ao Distrito Federal e aos Municípios. (BRASIL, 2008, p. 137, grifo nosso).

Essas são atribuições da União, conforme disposto no parágrafo 1 do artigo 211 da Constituição Federal, texto esse que subsidia o Decreto nํ 6.755/2009.

Para atender à diretriz XII do Plano de Metas, em 2009 o Governo Federal instituiu, através do Decreto no 6.755, a Política Nacional de Formação de Profissionais do Magistério da Educação Básica, disciplinou a atuação da Capes no fomento a programas de formação inicial e 
continuada e encaminhou outras providências. Esse decreto, em seu artigo 1으, parágrafo único, dispunha:

[...] fica instituída a Política Nacional de Formação de Profissionais do Magistério da Educação Básica, com a finalidade de organizar, em regime de colaboração entre a União, os Estados, o Distrito Federal e os Municípios, a formação inicial e continuada dos profissionais do magistério para as redes públicas da educação básica. 0 disposto no caput do Decreto será realizado na forma dos Artigos 61 a 67 da Lei no 9.394, de 20 de dezembro de 1996, e abrangerá as diferentes modalidades da educação básica.

Nesse cenário, as Instituições de Ensino Superior devem propor cursos que atendam às demandas regionais, tendo como suporte os fóruns estaduais permanentes de apoio à formação docente.

\begin{abstract}
Os Fóruns são órgãos colegiados que têm como finalidade organizar, também em regime de colaboração entre os entes federados, a formação inicial e continuada dos profissionais do magistério para as redes públicas da educação básica. Suas atribuições são: elaborar e acompanhar planos estratégicos com base no diagnóstico e na identificação das necessidades de formação do magistério das redes públicas, apoiado no censo escolar da educação básica: articular ações, otimizar recursos e potencializar esforços em interação com os sistemas de ensino e instituições formadoras sediadas no estado. (GATTI, 2011, p. 54).
\end{abstract}

Portanto, o regime de colaboração previsto no caput do artigo ora mencionado e também no parágrafo 1으 do artigo 62 da Lei no 12.056/2009, que fora acrescido à Lei no 9.394/1996, que estabelece as Diretrizes e Bases da Educação Nacional e que trata especificamente da formação inicial e continuada, bem como da capacitação dos profissionais de magistério, embasa também a política nacional de formação de professores, em conformidade com o que se encontra prescrito no artigo 2으, inciso III, do Decreto no 6.755/2009:

Art. 2 São princípios da Política Nacional de Formação de Profissionais do Magistério da Educação Básica: [...] III - a colaboração constante entre os entes federados na consecução dos objetivos da Política Nacional de Formação de Profissionais do Magistério da Educação Básica, articulada entre o Ministério da Educação, as instituições formadoras e os sistemas e Redes de ensino.

O artigo exposto apresenta como um dos princípios dessa política a colaboração, evidenciando que o alcance dos objetivos propostos ocorrerá mediante a permanente articulação entre o MEC, as instituições formadoras e os sistemas e redes de ensino.

Educação \& Formação, Fortaleza, v. 2, n. 6, p. 54-69, set./dez. 2017

DOI: http://dx.doi.org/10.25053/edufor.v2i6.2011

http://seer.uece.br/redufor 
É inegável, portanto, que a Política Nacional de Formação de Profissionais do Magistério da Educação Básica (BRASIL, 2009a) pode ser considerada uma alternativa para a correção dos desvios pertinentes à formação docente, buscando dirimir as desigualdades dessa área, baseando-se, sobretudo, nos seguintes princípios: "articulação entre a teoria e a prática no processo de formação docente"; "importância do projeto formativo, assegurando organicidade ao trabalho e garantindo sólida base teórica e interdisciplinar"; e "importância do docente no processo educativo da escola e de sua valorização profissional, traduzida em políticas permanentes de estímulo à profissionalização", entre outros (BRASIL, 2009a).

Dessa forma, o Parfor (BRASIL, 2009a), criado pela Portaria Normativa no 9 do MEC, como forma mais visível de operacionalização dessa política, prevê organizar as demandas e ofertas dos cursos de formação inicial e continuada do país.

\title{
4 A PARTICIPAÇÃO DAS IES
}

De acordo com o MEC (CAPES, 2013a), as IES oferecem turmas especiais de formação requerida na LDBEN aos professores em cursos de:

\begin{abstract}
I. Primeira Licenciatura - para docentes ou tradutores intérpretes de Libras em exercício na rede pública da educação básica que não tenham formação superior ou que mesmo tendo essa formação se disponham a realizar curso de licenciatura na etapa/disciplina em que atua em sala de aula; II. Segunda Licenciatura - para professores licenciados que estejam em exercício há pelo menos três anos na rede pública de educação básica e que atuem em área distinta da sua formação inicial, ou para profissionais licenciados que atuam como tradutor intérprete de Libras na rede pública de educação básica; III. Formação Pedagógica - para docentes ou tradutores intérpretes de Libras, com nível superior em curso que não seja de Licenciatura, que se encontram no exercício da docência na rede pública da educação básica.
\end{abstract}

Nessa perspectiva, vale frisar que o artigo 5 으, parágrafo $2 \stackrel{0}{ }$, desse decreto explicita “[...] promover a plena utilização da capacidade instalada das instituições públicas de educação superior", fazendo parte, portanto, do plano estratégico do MEC.

O procedimento $\mathrm{n}$ - $5^{1}$ apresentado pelo decreto ressalta que as IES devem firmar sua participação no programa por meio do Termo de Adesão ao Acordo de Cooperação Técnica,

1 Procedimento no 5: Das Instituições de Educação Superior (IES): 5.1 A participação das IES se dá por meio de firmatura de Termo de Adesão ao Acordo de Cooperação Técnica.

Educação \& Formação, Fortaleza, v. 2, n. 6, p. 54-69, set./dez. 2017

DOI: http://dx.doi.org/10.25053/edufor.v2i6.2011

http://seer.uece.br/redufor 
desde que estejam credenciadas no Sistema de Regulação do Ensino Superior, com avaliação do MEC, igual ou superior a 3 no Índice Geral de Curso (IGC) - (CAPES, 2013a).

Inicialmente o Parfor propalou restrição à participação somente de Ipes, mas posteriormente aderiu-se a IES confessionais e comunitárias com larga tradição em formação de professores no país. Essa restrição veda o financiamento público a programas desenvolvidos por IES privadas, exceto às confessionais e comunitárias. As Ipes são financiadas com bolsas para os professores ministrantes dos cursos, oferecendo também recursos para o custeio e aquisição de bibliografia. Recentemente a Capes divulgou o Edital no 030/2013, o qual tornou pública a chamada para as IES privadas sem fins lucrativos para participarem do Parfor a partir de 2014, conforme processo no 23038.003072/2013-18 (CAPES, 2013b). Os resultados desse processo elencam 32 instituições habilitadas para a realização do Parfor, sendo dez no estado ${ }^{2}$ do Rio Grande do Sul, oito em Santa Catarina e quatorze em São Paulo.

No tocante ao quadro de vagas nas Ipes, sabe-se, portanto, que essa demanda perpassava a esteira dos acontecimentos educacionais no Brasil, sendo responsável pela criação aligeirada dos sistemas de educação superior privados no país, que, de certa forma, não ofereciam, muitas vezes, qualidade, condições de oferta e adequação estrutural para atender àqueles que não conseguiam vagas nas instituições públicas.

Na primeira etapa de execução do Parfor, 76 instituições públicas de educação, sendo 48 federais, 28 estaduais e 14 universidades comunitárias aderiram ao plano, atingindo 21 estados da Federação (BRASIL, 2009a).

Quanto às ofertas de vagas disponibilizadas pelas IES, o decreto que institui o Parfor ( $\mathrm{n}$ 6.755/2009) outorga, em seu artigo 70, que o “[...] atendimento à necessidade por formação inicial de profissionais do magistério dar-se-á pela ampliação das matrículas oferecidas em cursos de licenciatura e Pedagogia pelas instituições públicas de educação superior", além de que os alunos selecionados aproveitarão a capacidade instalada em cursos de licenciatura e de Pedagogia das instituições que aderirem ao plano, bem como o atendimento regular da demanda futura em cursos na modalidade presencial e a distância.

\footnotetext{
2 É importante registrar que a chamada desse edital voltava-se às IES privadas sem fins lucrativos que deveriam estar sediadas nos estados do Rio Grande do Sul, Rondônia, Santa Catarina e São Paulo, cujo Fórum Estadual Permanente de Apoio à Formação Docente solicitou abertura de Edital para o chamamento de IES privadas sem fins lucrativos.
}

Educação \& Formação, Fortaleza, v. 2, n. 6, p. 54-69, set./dez. 2017

DOI: http://dx.doi.org/10.25053/edufor.v2i6.2011

http://seer.uece.br/redufor 
Em 2010, foram oferecidas mais de 300.000 vagas. Somando-se essa oferta às vagas disponibilizadas em 2009, chega-se a um total de 362.471 vagas. Assim, o quantitativo de vagas abertas em 2009 e 2010 extrapolou a previsão realizada pela Capes inicialmente, que visava ofertar 331.000 vagas nos três primeiros anos de execução do plano.

Até dezembro de 2011, 86 IES sediadas em 22 estados ofertavam turmas especiais. Desse total de instituições participantes, 31 eram federais $(36,05 \%), 28$ eram privadas sem fins lucrativos (32,56\%), 26 eram estaduais (30,23\%) e uma era municipal $(1,16 \%)$.

Quanto à evolução do número de IES que participaram do Parfor, pode-se constatar que houve um avanço significativo entre os anos de 2009 e 2011. Os últimos dados do Instituto Nacional de Estudos e Pesquisas Educacionais Anísio Teixeira (INEP, 2013) sinalizam que 141 IES em 25 estados oferecem cursos de licenciatura presenciais e a distância ${ }^{3}$. Nessa lógica, para 2014.2, o MEC disponibilizou 39.476 vagas, sendo 26.314 para a formação inicial - 1a licenciatura -, 12.018 para a 2 a licenciatura e 1.144 vagas para a formação pedagógica. Vale frisar que a 1a licenciatura tem a duração de três anos quando ofertada na modalidade presencial e de quatro anos quando a distância. Já a 2ª licenciatura e a formação pedagógica têm a duração de, no máximo, dois anos.

\section{CONSIDERAÇÕES FINAIS}

O Parfor é uma política nacional de formação de professor da Educação Básica no Brasil. Apesar do investimento voltado para a formação de professores nas últimas décadas, a realidade que transcorre dessa formação precisa ser analisada, uma vez que as condições para efetivação de seu funcionamento e desenvolvimento envolvem adequação salarial, estrutural, organizacional e humana, além dos saberes de mundo, da teoria e da prática de cada professor.

É inegável, portanto, que o avanço na qualidade da formação superior no país ocorre por meio dos programas e pelo esforço dos próprios professores na busca de preparo para o exercício da profissão, pois estes tentam conciliar, na medida do possível, seus respectivos horários de trabalho às suas formações, sem se afastarem de suas funções. Afinal, aos estudantes do Parfor é negada a possibilidade de afastar-se de suas atividades laborais para dedicar-se exclusivamente ao rendimento em sala, sem contar que a grande maioria dos participantes é

3 Os cursos a distância são realizados pela Universidade Aberta do Brasil (UAB), criada pelo Decreto no 5.800/2006.

Educação \& Formação, Fortaleza, v. 2, n. 6, p. 54-69, set./dez. 2017

DOI: http://dx.doi.org/10.25053/edufor.v2i6.2011

http://seer.uece.br/redufor 
composta por mulheres, significando, muitas vezes, uma tripla jornada imposta pela sociedade, que se desenvolve no âmbito familiar entre marido e filhos, entre outros, na perspectiva de melhor aprimoramento pessoal e profissional, o que, consequentemente, contribui para a melhoria da qualidade na educação.

À luz das mudanças ocorridas em resposta aos debates promovidos pelos movimentos sociais, a década de 1990 foi avaliada como um período marcante para vislumbrar os profissionais da educação como referências essenciais para as transformações sociais. Assim, melhorar o nível da educação, sobretudo da Educação Básica, é uma preocupação retratada nas políticas públicas para a educação brasileira que têm como foco a formação e o desempenho dos professores para a melhoria de seus padrões e da qualidade em todo o sistema educacional, apesar das diferenças regionais serem consideradas marcantes (INEP, 2008).

O Parfor, como política nacional de formação de professores da rede pública, é, pois, uma iniciativa recente, considerada plausível e relevante para assegurar o que determina a LDBEN no 9.394/1996 no tocante à formação dos profissionais da educação, bem como para melhorar a qualidade da educação brasileira, uma vez que a educação é um organismo vivo e o professor é a peça fundamental para o crescimento cultural, social e econômico da nação. No entanto, essa responsabilidade pelo êxito ou fracasso atribuída ao professor constitui-se como ação delicada e cruel, visto que o Governo lança as propostas de melhoria da educação fundamentadas nas necessidades econômicas vigentes, mas muitas vezes não oferece condições favoráveis para a efetivação dessas propostas ou se esquiva de suas responsabilidades frente às demandas sociais.

É pertinente registrar que as metas estabelecidas inicialmente no plano divergem do contexto real, pois a lei da oferta e da demanda é solidificada mais como cursos ofertados e nem sempre corresponde aos anseios dos profissionais em formação, ou seja, à própria demanda, não existindo também especificidades quanto às unidades articuladoras pertinentes à função de cada uma, gerando, sobretudo, lacunas ou brechas para que muitas prefeituras se isentem de suas responsabilidades, não oferecendo sequer condições para que os professores possam frequentar as aulas presenciais, propiciando, com isso, transtornos financeiros e descontentamentos por parte dos protagonistas desse processo.

Educação \& Formação, Fortaleza, v. 2, n. 6, p. 54-69, set./dez. 2017 
Diante do exposto, faz-se necessária a reavaliação dos princípios e dos objetivos propostos nesse plano, de forma que sejam redimensionados e suscetíveis ao sucesso, já que esse plano faz parte de uma ação inovadora da educação no Brasil.

Destarte, a política de formação de professores vigente no país é considerada como um canal favorável à formação dos docentes em exercício na Educação Básica. Porém, nota-se a necessidade de estudos mais aprofundados acerca dessa temática, com o propósito de aclarar e investigar se os princípios estabelecidos têm sido cumpridos na íntegra entre as instâncias federal, estadual e, principalmente, municipal, ampliando, assim, a colaboração e o fortalecimento desse plano tão importante para o professor em formação, na condição de profissional competente, responsável e comprometido com a docência e a transformação social.

Nesse contexto, corroboram-se as ideias de Gatti e Barreto (2009), que defendem o Parfor como uma iniciativa recente em pleno desenvolvimento. Apesar dos entraves burocráticos e econômicos erguidos desde a sua implantação, deve-se aguardar um pouco mais de tempo para avaliá-lo de forma mais elaborada entre o que foi proposto no Decreto $n$ o 6.755/2009 e a realidade observada no decorrer de sua execução. Contudo, não se pode deixar de evidenciar que o Parfor tem sido uma oportunidade enriquecedora para os professores da rede pública de ensino, que, além de apreenderem conhecimentos, também promovem mudanças de postura que contribuem para uma prática pedagógica exitosa, sendo, portanto, um instrumento a favor da educação pública de qualidade da nação brasileira.

Conclui-se, assim, que a temática em questão encontra-se num amplo processo de discussão nacional, o que possibilita afirmar o inacabamento deste estudo, visto que essa temática será focalizada e complementada em outros momentos pelas contribuições de muitos pesquisadores.

\section{REFERÊNCIAS}

ABDALlA, M. F. B. Políticas de formação de professores: desafios e perspectivas. Porto: Universidade do Porto, 2012.

BRASIL. Constituição de 1988. Constituição da República Federativa do Brasil. Diário Oficial [da] República Federativa do Brasil, Poder Executivo, Brasília, DF, 5 out. 1988.

Educação \& Formação, Fortaleza, v. 2, n. 6, p. 54-69, set./dez. 2017

DOI: http://dx.doi.org/10.25053/edufor.v2i6.2011

http://seer.uece.br/redufor 
BRASIL. Decreto no 5.800, de 8 de junho de 2006. Dispõe sobre o Sistema Universidade Aberta do Brasil - UAB. Diário Oficial [da] República Federativa do Brasil, Poder Executivo, Brasília, DF, 9 jun. 2006.

BRASIL. Decreto no 6.094, de 24 de abril de 2007. Dispõe sobre a implementação do Plano de Metas Compromisso Todos pela Educação, pela União Federal, em regime de colaboração com Municípios, o Distrito Federal e os Estados. Diário Oficial [da] República Federativa do Brasil, Poder Executivo, Brasília, DF, 25 abr. 2007.

BRASIL. Decreto no 6.755, de 29 de janeiro de 2009. Institui a Política Nacional de Formação de Profissionais do Magistério da Educação Básica, disciplina a atuação da Coordenação de Aperfeiçoamento de Pessoal de Nível Superior - Capes no fomento a programas de formação inicial e continuada, e dá outras providências. Diário Oficial [da] República Federativa do Brasil, Poder Executivo, Brasília, DF, 30 jan. 2009a.

BRASIL. Decreto no 7.219, de 24 de junho de 2010. Dispõe sobre o Programa Institucional de Bolsa de Iniciação à Docência - PIBID e dá outras providências. Diário Oficial [da] República Federativa do Brasil, Poder Executivo, Brasília, DF, 25 jun. 2010.

BRASIL. Emenda Constitucional no 59, de 2009. Acrescenta § 3o ao art. 76 do Ato das Disposições Constitucionais Transitórias para reduzir, anualmente, a partir do exercício de 2009, o percentual da Desvinculação das Receitas da União incidente sobre os recursos destinados à manutenção e desenvolvimento do ensino de que trata o art. 212 da Constituição Federal, dá nova redação aos incisos I e VII do art. 208, de forma a prever a obrigatoriedade do ensino de quatro a dezessete anos e ampliar a abrangência dos programas suplementares para todas as etapas da educação básica, e dá nova redação ao § 40 do art. 211 e ao § 30 do art. 212 e ao caput do art. 214, com a inserção neste dispositivo de inciso VI. Diário Oficial [da] República Federativa do Brasil, Poder Executivo, Brasília, DF, 12 nov. 2009b.

BRASIL. Lei no 9.394, de 20 de dezembro de 1996. Estabelece as Diretrizes e Bases da Educação Nacional. Diário Oficial [da] República Federativa do Brasil, Poder Executivo, Brasília, DF, 21 dez. 1996.

BRASIL. Lei no 12.056, de 13 de outubro de 2009. Acrescenta parágrafos ao art. 62 da Lei no 9.394, de 20 de dezembro de 1996, que estabelece as Diretrizes e Bases da Educação Nacional. Diário Oficial [da] República Federativa do Brasil, Poder Executivo, Brasília, DF, 14 out. 2009c.

BRASIL. Lei no 12.796, de 4 de abril de 2013. Altera a Lei № 9.394, de 20 de dezembro de 1996, que estabelece as Diretrizes e Bases da Educação Nacional, para dispor sobre a formação dos profissionais da educação, e dá outras providências. Diário Oficial [da] República Federativa do Brasil, Poder Executivo, Brasília, DF, 5 abr. 2013.

BRASIL. Política de Educação Especial na Perspectiva Inclusiva. Brasília, DF: SEESP/MEC, 2008.

Educação \& Formação, Fortaleza, v. 2, n. 6, p. 54-69, set./dez. 2017

DOI: http://dx.doi.org/10.25053/edufor.v2i6.2011

http://seer.uece.br/redufor 
BRASIL. Portaria Normativa no 9, de 30 de junho de 2009. Institui o Plano Nacional de Formação dos Professores da Educação Básica no âmbito do Ministério da Educação. Diário Oficial [da] República Federativa do Brasil, Poder Executivo, Brasília, DF, 10 jun. 2009d.

BRASIL. Rede Nacional de Formação Continuada de Professores da Educação Básica: orientações gerais. Brasília, DF: MEC/SEB, 2005.

BRASIL. Resolução CNE/CP n 1, de 11 de fevereiro de 2009. Estabelece Diretrizes Operacionais para a implantação do Programa Emergencial de Segunda Licenciatura para Professores em exercício na Educação Básica Pública a ser coordenado pelo MEC em regime de colaboração com os sistemas de ensino e realizado por instituições públicas de Educação Superior. Diário Oficial [da] República Federativa do Brasil, Poder Executivo, Brasília, DF, 2 fev. 2009e.

CAPES. Edital no 030/2013. Torna pública a chamada para as Instituições de Ensino Superior Privadas sem fins lucrativos para participarem do Plano Nacional de Formação dos Professores da Educação Básica (Parfor). Brasília, DF: Capes, 2013b.

CAPES. Manual operativo do Parfor. Brasília, DF, 2013a. Disponível em: <www.capes.gov.br/ images/stories/download/legislacao/manualoperativoparfor-mar13.pdf>. Acesso em: 5 abr. 2013.

FREIRE, P. Pedagogia da autonomia: saberes necessários à prática educativa. 33. ed. São Paulo: Paz e Terra, 2006.

GATTI, B. A. Políticas docentes no Brasil: um estado da arte. Brasília, DF: Unesco, 2011.

GATTI, B. A.; BARRETO, E. S. S. (Coord.). Professores do Brasil: impasses e desafios. Brasília, DF: Unesco, 2009.

GHIRALDELLI JÚNIOR, P. História da educação. 2. ed. São Paulo: Cortez, 2001.

INEP. Censo da Educação Superior 2013. Brasília, DF: MEC, 2013.

KOSIK, K. Dialética do concreto. 7. ed. São Paulo: Paz e Terra, 2002.

LIBÂNEO, J. C.; PIMENTA, S. G. Formação de profissionais da educação: visão crítica e perspectiva de mudança. Revista Educação e Sociedade, Campinas, v. 20, n. 68, p. 239-277, 1999.

Recebido em 2 de setembro de 2016.

Aceito em 27 de outubro de 2017.

Educação \& Formação, Fortaleza, v. 2, n. 6, p. 54-69, set./dez. 2017

DOI: http://dx.doi.org/10.25053/edufor.v2i6.2011

http://seer.uece.br/redufor 